\title{
EDITORIAL
}

\section{A COASTal view: where prior beliefs and uncertainty collide}

\author{
Mark J. Peters ${ }^{1,2^{*}}\left(\mathbb{0}\right.$, William Macharia ${ }^{3}$ and Elizabeth Molyneux ${ }^{4}$
}

() 2021 Crown

The Children's Oxygen Administration Strategies Trial (COAST) was an ambitious project based in Uganda and Kenya. The target population was children with severe pneumonia as assessed by presentation of peripheral oxygen saturation into two strata (hypoxaemia: $\mathrm{SpO}_{2} 80-92 \%$ and severe hypoxaemia: $\left.\mathrm{SpO}_{2}<80 \%\right)$. The comparisons were between high-flow humidified nasal therapy (HFNT) and standard low-flow nasal oxygen in the severe hypoxaemia stratum, but also in a fractional factorial design of more liberal oxygen use vs. permissive hypoxaemia in the less severe stratum. The primary outcome measure was mortality at $48 \mathrm{~h}$. The trial was conducted by a team with an outstanding track record of delivering large pragmatic and practice-changing trials in low-income settings. We had the privilege of being independent members of the Trial Steering Committee (TSC).

Unfortunately, and unusually for this team, the trial was unable to recruit the prespecified target of 4200 acutely ill children. However, the analysis of the 1842 children enrolled does provide important data. A pneumonia diagnosis was supported by $\mathrm{X}$-ray changes in $1111 / 1842=60.3 \%$ of children. Crucially, the observed deaths in the less severe stratum of the trial $\left(\mathrm{SpO}_{2}\right.$ 80-92\%) were much lower than the investigators had anticipated (observed mortality $23 / 1454=1.6 \%$ vs. expected mortality $=9 \%$ ). Perhaps the most striking result in this stratum was that mortality amongst the permissive hypoxaemia group was the same as for those given low-flow oxygen. Given the recent results of the

\footnotetext{
*Correspondence: mark.peters@ucl.ac.uk

${ }^{2}$ Respiratory Critical Care and Anaesthesia Unit, University College London, Great Ormond Street Hospital Institute of Child Health, NIHR Biomedical Research Centre, London WC1N 1EH, UK

Full author information is available at the end of the article
}

Higher or Lower Oxygenation Targets for Acute Hypoxaemia Respiratory Failure (HOT-ICU), [1] Conservative Oxygen Therapy during Mechanical Ventilation in the ICU (ICU-ROx) [2] and Conservative versus liberal oxygenation targets pilot trial in critically ill children (Oxy-PICU) [3], this is perhaps the result we would now expect, but this was far from certain when COAST was first planned. This finding has important implications for oxygen use which is a scarce resource in this setting. Only $15 \%$ of the less severe stratum assigned to permissive hypoxaemia required any supplemental oxygen. Non-significant differences in point estimates hinted that high-flow nasal cannula (HFNC) might be superior to low-flow oxygen but the reduced study power from lower death rates and incomplete recruitment have left this question open. Interestingly, HFNC in air alone is raised as a possible strategy which may have value where oxygen supply is scarce. These important findings should generate new investigations to prioritise limited resources in low- and middle-income countries.

Perhaps the most interesting learning from COAST is to consider why this trial was not completed as planned. The investigators are a highly respected team with international and local expertise and an extraordinary record of delivering pragmatic trials in this setting. Their landmark Fluid Expansion in Severely Ill Children [4] and Transfusion in African Children (TRACT) trials [5, 6] illustrate this.

So how did such an experienced team, with us on the TSC, miss the target of 4200 patients by so far? The late British prime minister Harold Macmillan described unpredictability as arising from "events, dear boy, events". COAST indeed suffered from 'events'. One being a doctors' strike in Kenya which significantly delayed opening for recruitment in 2017.

The other 'event' was more complex. It involved vocal opposition to the trial by staff involved in research

\section{Springer}




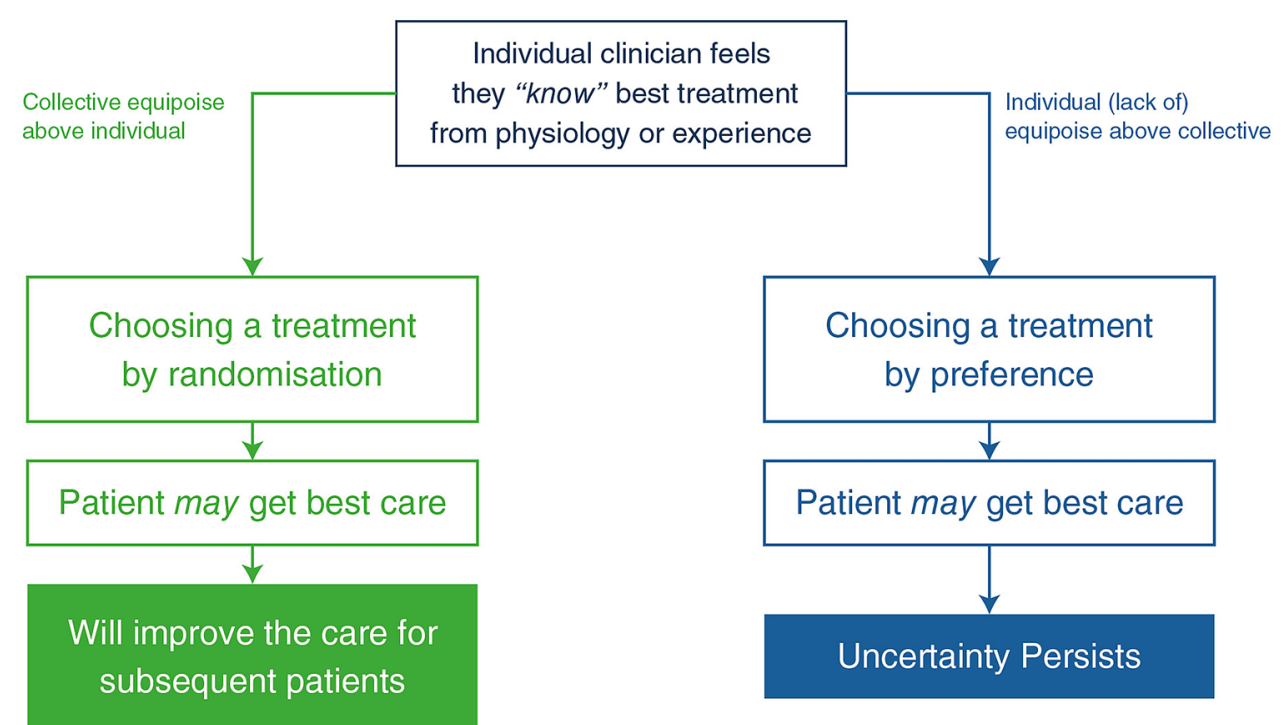

Fig. 1 The challenge of personal vs. collective equipoise in clinical trials. Most clinicians favour specific treatment approaches based on physiology or experience. Ideally, a clinical trial permits an individual to set aside their prior beliefs to reduce uncertainty. Trials that address long-held assumptions such as the risks and benefits of supplemental oxygen have to face this challenge

governance processes in Uganda. Despite all relevant advance approvals, trial recruitment was stopped in Uganda three times. In contrast, the Kenya Paediatric Association provided professional education and strong support for the study. Following supportive external reviews of the science, including three independent data monitoring committee reviews (indicating no safety concerns) and robust trial governance, recruitment was restarted twice in Uganda. The delays resulting from these pauses eventually rendered the recruitment target unfeasible during the existing funding envelope. We wonder if there is a possibility of an aligned ethics governance process across East Africa? This might catalyse the muchneeded growth for multiple-centre research in the region.

Having said that, we believe the challenges experienced by the COAST investigators overlap with those that every important trial has to face: how do we handle individual versus general equipoise? When the data do not permit us to make an evidenced-based recommendation between two approaches, most intensivists or acute care doctors will make a decision based on experience or inferences from physiology. Often this may be rewarded by an acute physiological response (increased blood pressure with fluid administration for example) but possible later harms may not be so visible. In our example, the same fluid bolus may subsequently contribute to worsening lung injury or heart failure. In other words, our perception of risks and benefits is subject to an availability bias as information becomes visible at different times. The observation that 'less-is-more' in most interventions in critical care does suggest that we frequently get this wrong. [7, 8] So, when a colleague is adamant that they will not use HFNC instead of continuous positive airway pressure (CPAP) [9], or tolerate a lower haemoglobin, [10] blood pressure [11] or oxygen target [3], how should we balance doctors' individual freedom to choose, within the area of true uncertainty that a trial is trying to address? (Fig. 1). We suspect all trialists will recognise this challenge. One approach is to engage with the doubter and encourage them to use the trial to resolve the question - which may prove them right! Another is to bemoan the lack of progress that must follow from not engaging in well-designed trials ('perpetuating ignorance'). This enthusiasm for trials does not remove the expectation that all trials are subject to rigorous peerreview and safety monitoring, and that they remain attentive to criticism and concerns as they are performed. But we have to be open to asking fundamental questions or we will only ever improve in small increments. Oxygen therapy has a peculiar place in many doctors' hearts which means they are reluctant to question its value. The more challenging the questions we ask, the more effort is needed in advance in consultation and spreading the rationale for a study. Clinical trials are not 'just science', they include public relations.

Ultimately it is up to trialists to design studies that can address clinically important questions and carry as much of the community with them as possible in addressing this. COAST took on very challenging questions. It recorded an extraordinarily low mortality compared to 
expectations. In the face of serious challenges, the investigators have made future studies in this area possible by undermining strongly held prior beliefs regarding the role of oxygen therapy and its delivery.

\section{Author details}

1 Paediatric Intensive Care Unit, Great Ormond Street Hospital for Children NHS Trust, London, UK. ${ }^{2}$ Respiratory Critical Care and Anaesthesia Unit, University College London, Great Ormond Street Hospital Institute of Child Health, NIHR Biomedical Research Centre, London WC1N 1EH, UK. ${ }^{3}$ Department of Paediatric and Child Health, Aga Khan University, 3rd Parklands Avenue, Box 30270, Nairobi 00100, Kenya. ${ }^{4}$ Department of Paediatric and Child Health, College of Medicine, Box 360, Blantyre, Malawi.

\section{Funding}

This editorial was, in part, undertaken at Great Ormond Street Hospital/UCL Institute of Child Health, which received a proportion of funding from the Department of Health's NIHR Biomedical Research Centre's funding scheme.

\section{Declarations}

\section{Conflicts of interest}

All authors were independent members (Chaired by EM) of the COAST Trial Steering Committee. MJP is Chief Investigator on the UK National Institute of Health Research Heath Technology Assessment programme trial of Conservative vs Liberal Oxygenation in Critically III children.

\section{Publisher's Note}

Springer Nature remains neutral with regard to jurisdictional claims in published maps and institutional affiliations.

Received: 30 March 2021 Accepted: 7 April 2021

Published online: 27 April 2021

\section{References}

1. Schjørring OL, Klitgaard TL, Perner A et al (2021) Lower or higher oxygenation targets for acute hypoxemic respiratory failure. N Engl J Med. https://doi.org/10.1056/NEJMoa2032510

2. ICU-ROX Investigators and the Australian and New Zealand Intensive Care Society Clinical Trials Group, Mackle D, Bellomo R et al (2020) conservative oxygen therapy during mechanical ventilation in the ICU. N Engl J Med 382:989-998. https://doi.org/10.1056/NEJMoa1903297

3. Peters MJ, Jones GAL, Wiley D et al (2018) Conservative versus liberal oxygenation targets in critically ill children: the randomised multiplecentre pilot Oxy-PICU trial. Intensive Care Med. https://doi.org/10.1007/ s00134-018-5232-7

4. Maitland K, Akech SO, Russell EC (2011) Mortality after fluid bolus in african children. N Engl J Med 365:1348-1353

5. Maitland K, Kiguli S, Olupot-Olupot P et al (2019) Immediate transfusion in african children with uncomplicated severe anemia. N Engl J Med 381:407-419. https://doi.org/10.1056/NEJMoa1900105

6. Maitland K, Olupot-Olupot P, Kiguli S et al (2019) Transfusion volume for children with severe anemia in Africa. N Engl J Med 381:420-431. https:// doi.org/10.1056/NEJMoa1900100

7. Perner A, Hjortrup PB, Pettilä V (2018) Focus on randomised clinical trials. Intensive Care Med 44:2257-2259. https://doi.org/10.1007/ s00134-018-5468-2

8. Kox M, Pickkers P (2013) "Less is more" in critically ill patients: not too intensive. JAMA Intern Med 173:1369-1372. https://doi.org/10.1001/ jamainternmed.2013.6702

9. Orzechowska I, Sadique MZ, Thomas K et al (2020) First-line support for assistance in breathing in children: statistical and health economic analysis plan for the FIRST-ABC trial. Trials 21:903. https://doi.org/10.1186/ s13063-020-04818-w

10. Lacroix J, Hébert PC, Hutchison JS et al (2007) Transfusion strategies for patients in pediatric intensive care units. N Engl J Med 356:1609-1619. https://doi.org/10.1056/NEJMoa066240

11. Matettore A, Ray S, Harrison DA et al (2019) Paediatric intensive care admission blood pressure and risk of death in 30,334 children. Intensive Care Med 45:1482-1483. https://doi.org/10.1007/s00134-019-05638-6 